\title{
Analysis of Unsignalized Intersection
}

\author{
B.Ramkumar ${ }^{1}$, B.Adinarayana ${ }^{2}$, Mane $\mathrm{Sr}$ Rohith $^{3}$ \\ ${ }^{1}$ M.Tech student, ${ }^{2,3}$ Assistant Professor \\ Department of Civil Engineering \\ Aurora's Scientific Technological and Research Academy
}

\begin{abstract}
Signal timing is the technique which traffic engineers use to determine who has the right-of-way at an intersection. Signal timing involves deciding how much green time the traffic lights shall provide at an intersection approach, how long the pedestrian walk signal should be, and many numerous other factors.
\end{abstract}

Traffic volume studies are conducted to determine the number, movements, and classifications of roadway vehicles at a given location. These data can help identify critical flow time periods, determine the influence of large vehicles or pedestrians on vehicular traffic flow, or document traffic volume trends. The length of the sampling period depends on the type of count being taken and the intended use of the data recorded. For example, an intersection count may be conducted during the peak flow period. If so, manual count with 15 minute intervals could be used to obtain the traffic volume data.

Webster's method is a rational approach for signal design. The design is simple and is totally based on formulae's laid down by Webster. In this method, the total cycle of the signal is determined which forms a total least delay occurring at signal (least delay of road user).

\section{INTRODUCTION}

The problems of urban transportation are well known not just for traffic engineers but to people in all walks of life. Overcrowded and congested with vehicles of all type creating lots of traffic problems and pollutions making the cities a veritable jungle. The problem as exist today can hardly be del inked from its problem of town planning and its implementation. In fact bottlenecks in the urban transportation system have risen because the cities are not planned and built for supporting the volume of population they are given shelter today. Travel has become inherently risky activity in cities.

Traffic consists on Indian roads of bi-directional freedom traffic such as two or three wheeled vehicles and uni-directional vehicles such as four wheelers. Or rejected by various modes of traffic. To prevent traffic accidents, conflicting traffic streams are separated either in space or in time.

\section{Traffic StUdies}

Traffic studies or surveys are carried out to analyze the traffic Characteristics. These studies help in deciding the geometric design features and control for safe and efficient traffic movement. The various traffic studies generally carried out are:

- Traffic study

- Speed studies

- Origin and destination study

- Traffic flow characteristics

- Traffic capacity study

- Parking studies

- Accident studies

\section{TrafFic Volume STUdY}

One of the fundamental measures of traffic on road system is the volume of traffic using the road in a given interval of time when the traffic is composed of a number of types of vehicles; it is the normal practice to convert the flow into equivalent P.C.U by using certain equivalency factor. The flow is expressed as PCU per hour. 


\section{Methods for Traffic Counts}

- Manual methods

- Combination of manual \& mechanical method

- Automatic Method

- Moving observer method

- Photographic method

\section{Methodology}

The signal design procedure involves six major steps. They include the

(1) Phase design

(2) Determination of amber time and clearance time

(3) Determination of cycle length

(4) Apportioning of green time

(5) The performance evaluation of the above design.

- The objective of phase design is to separate the conflicting movements in an intersection into various phases, so that movements in a phase should have no conflicts. If all the movements are to be separated with no conflicts, then a large number of phases are required.

- To illustrate various phase plan options, consider a four legged intersection with through traffic and right turns. Left turn is ignored

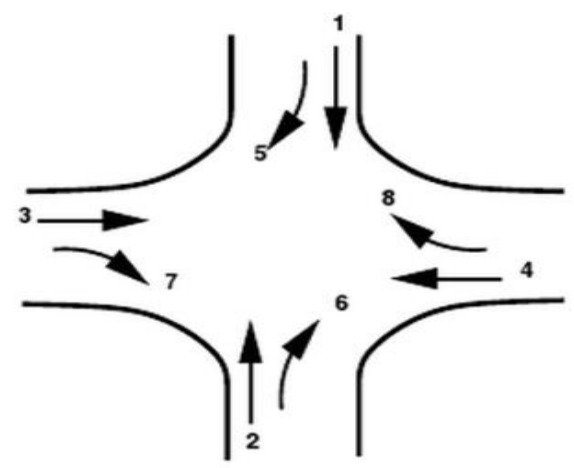

\subsection{Two Phase Signals}

Two phase system is usually adopted if through traffic is significant compared to the turning movements. Non-conflicting through traffic 3 and 4 are grouped in a single phase and non-conflicting through traffic 1 and 2 are grouped in the second phase. However, in the first phase flow 7 and 8 over some conflicts and are called permitted right turns.

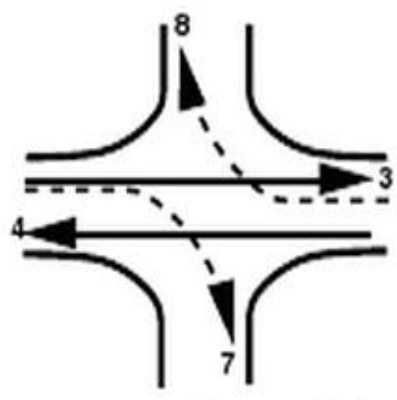

Phase $1\left(P_{1}\right)$

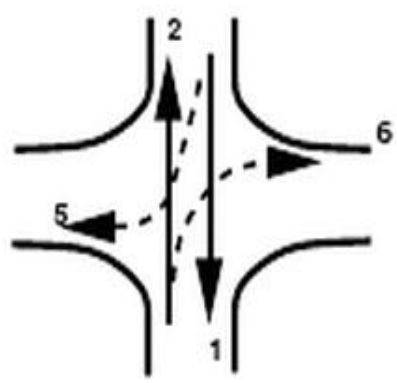

Phase $1\left(P_{2}\right)$ 


\subsection{Three Phase Signals}

Three phase signals are adopted for a three legged intersection, where there are two conflicting movements which are right turns for both the roads and two non conflicting movements which are through movements. The phase plan for this kind of signals is shown in the following figure. From fig. , phase 1 (p1) is provided by only allowing the non conflicting traffic 1 , phase 2 (p2) and phase 3 (p3) are provided by allowing the conflicting traffic 3 and 4 respectively.
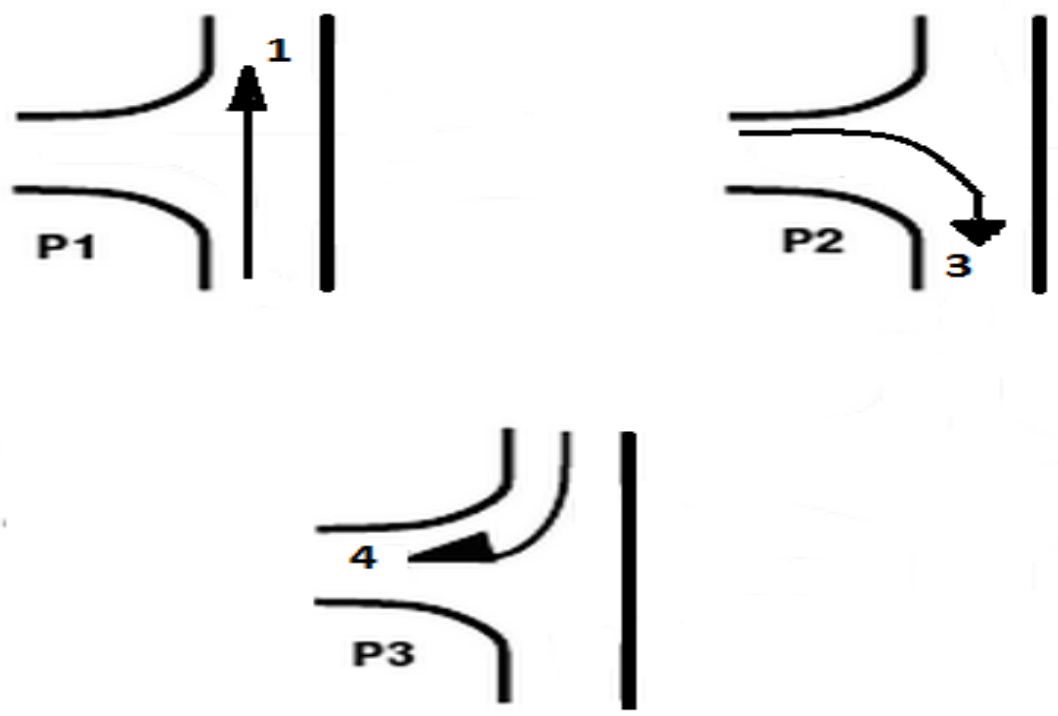

\subsection{Four Phase Signals}

There are at least three possible phasing options.. Where, flow from each approach is put into a single phase avoiding all conflicts. This type of phase plan is ideally suited in urban areas where the turning movements are comparable with through movements and when through traffic and turning traffic need to share same lane. This phase plan could be very inefficient when turning movements are relatively low.. The non-conflicting right turn flows 7 and 8 are grouped into a third phase. Similarly flows 5 and 6 are grouped into fourth phase. This type of phasing is very efficient when the intersection geometry permits to have at least one lane for each movement, and the through traffic volume is significantly high. This is rarely used in practice. There are five phase signals, six phase signals etc. They are normally provided if the intersection control is adaptive, that is, the signal phases and timing adapt to the real time traffic conditions.
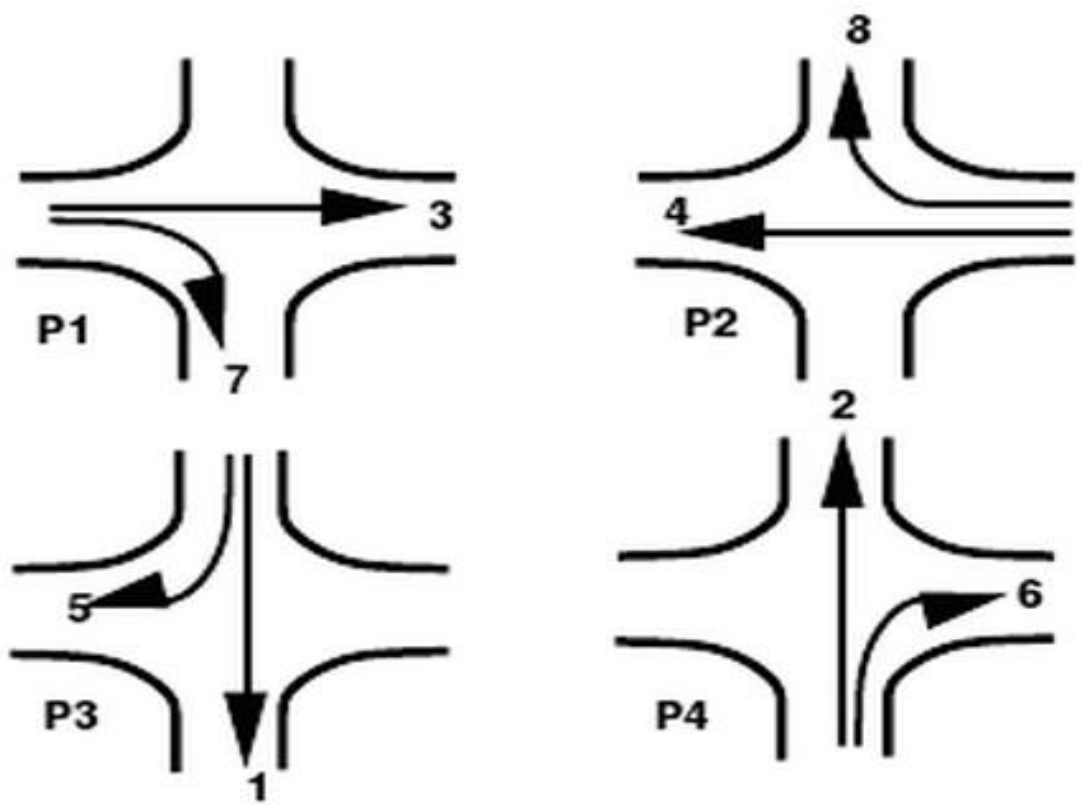


\subsection{Interval Design}

There are two intervals, namely the change interval and clearance interval, normally provided in a traffic signal. The purpose is to warn a driver approaching the intersection during the end of a green time about the coming of a red signal. They normally have a value of 3 to 6 seconds.

Institute of transportation engineers (ITE) has recommended a methodology for computing the appropriate length of change interval which is as follows:

$$
y=t+\frac{\mathrm{v} 85}{2 a+19.6 g}
$$

Where $y=$ length of yellow interval in seconds,

$\mathrm{t}=$ reaction time of the driver,

$\mathrm{v}_{85}=85$ th percentile speed of approaching vehicles in $\mathrm{m} / \mathrm{s}$,

$\mathrm{a}=$ deceleration rate of vehicles in $\mathrm{m} / \mathrm{s} 2$,

$\mathrm{g}=$ grade of approach expressed as a decimal.

Change interval can also be approximately computed as

$$
y=\frac{S S D}{v} ; \text { Where, }
$$

$\mathrm{SSD}=$ stopping sight distance and

$\mathrm{v}=$ speed of the vehicle.

\subsection{Cycle Time}

Cycle time is the time taken by a signal to complete one full cycle of iterations. i.e. one complete rotation through all signal indications. It is denoted by $\mathrm{C}$. The way in which the vehicles depart from an intersection when the green signal is initiated

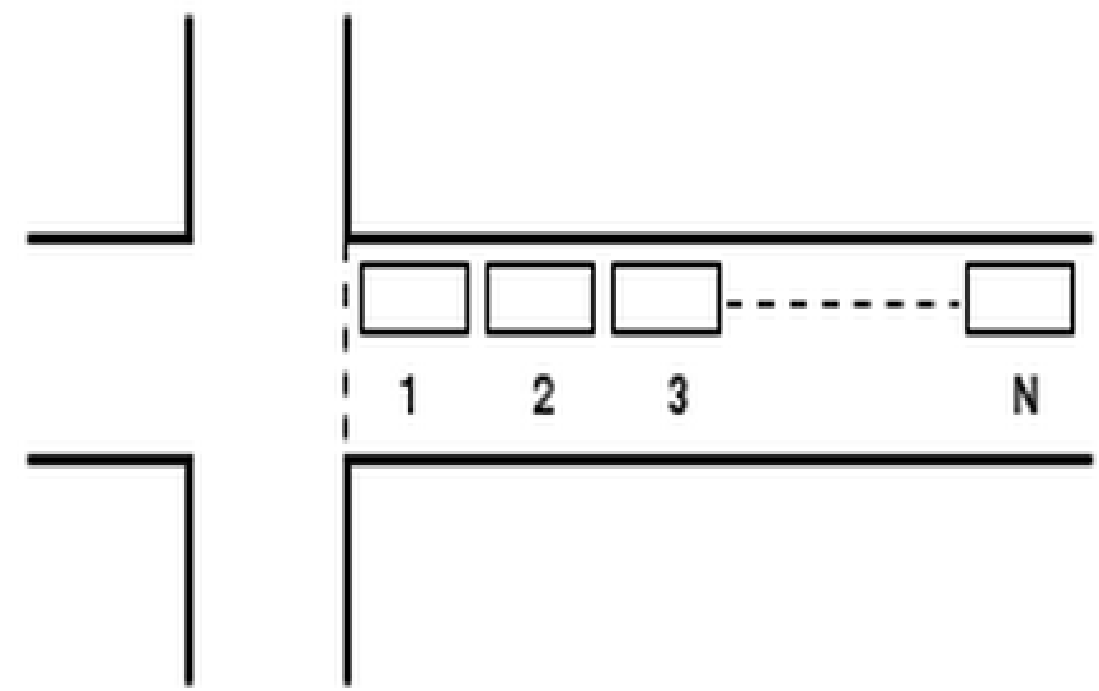

Illustrates a group of $\mathrm{N}$ vehicles at a signalized intersection, waiting for the green signal. As the signal is initiated, the time interval between two vehicles, referred as headway, crossing the curb line is noted. If every vehicles require $\mathrm{h}$ seconds of green time, and if the signal were always green, then $\mathrm{s}$ vehicles/per hour would pass the intersection.

Therefore,

$$
\mathrm{s}=\frac{3600}{h}
$$

Where; $\mathrm{s}=$ saturation flow rate in vehicles per hour of green time per lane,

$\mathrm{h}=$ saturation headway in seconds. Vehicles per hour of green time per lane. 


\section{ANALYSIS OF THREE LEgGED INTERSECTION}

A three legged intersection is similar to a ' $\mathrm{T}$ ' or ' $\mathrm{Y}$ ' shaped intersection. For designing a signal at three legged junction, firstly it should be analysed and then the signal is to be designed accordingly. Analysis of a three legged intersection contains understanding and analysing the traffic movement occuring at junction.

The main problems are:

- conflicting traffic,

- sudden crossing of pedestrians,

- $\quad$ sudden stopping of three wheelers

We considered this junction as a three legged intersection a signal should be provided mandatory to decrease the traffic jam, and to increase the adequate flow of traffic

Here we considered and analyzed this junction into 6 volumes.

$>$ V1 - from Balapur towards sagar ring road.

$>\mathrm{V} 2$ - Sagar ring road towards Balapur.

$>$ V3-Balapur to TKR kaman.

$>$ V4-TKR kaman to Sagar ring road.

$>$ V5-TKR kaman to Balapur.

$>$ V6- Sagar ring road to TKR kaman

Here v5 and v6 are free lefts hence they are not considered much. The main problem is with conflicting traffic which is from v3 i.e., traffic flow from TKR to Sagar ring road, causing traffic congestion to the primary traffic. Another volume v4 i.e. from Balapur to TKR conflicts with the priority running traffic. Hence a three phase signal is provided with the following amenities.

V1 signal to be categorized as $70 \mathrm{sec}$ on red with a $35 \mathrm{sec}$ green release followed.

V2 signalling to be $75 \mathrm{sec}$ on red with a $30 \mathrm{sec}$ green window.

Similarly,

- At V3 a 30sec red signal followed by a 20sec green signal.

- At V4 a $35 \mathrm{sec}$ red signal with a $22 \mathrm{sec}$ green signal are to be provided

- Hence a signal timer as per the above mentioned windows and timings is suggested to be installed. And to further decrease disturbances caused by the pedestrians zebra crossings are to be installed at the junctions and the pedestrians are to be guided across on reds.

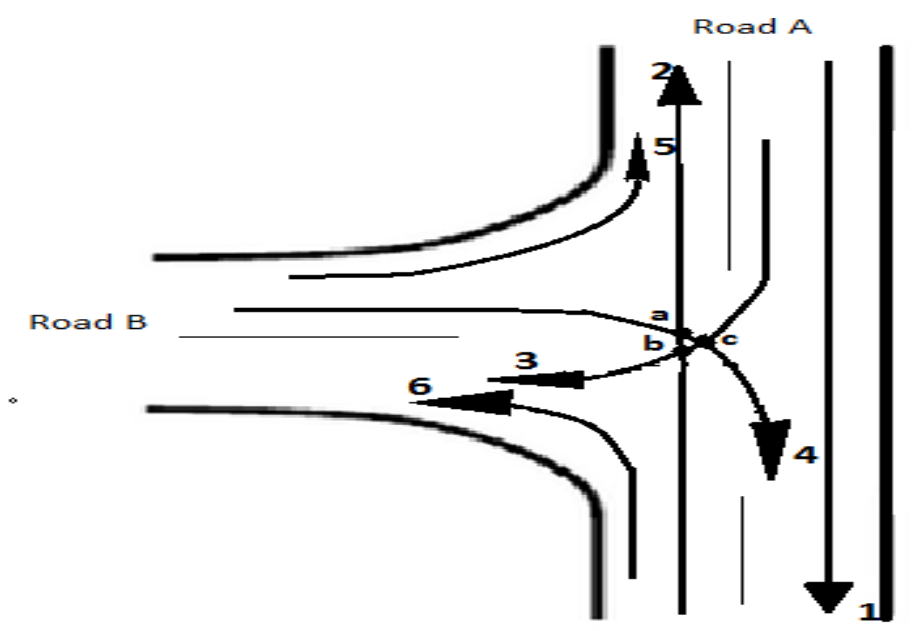

In this intersection (in fig.), the traffic movements are indicated as $1,2, \ldots 6$ and the conflict points are inditcated as a,b and $\mathrm{c}$. 


\section{B.Ramkumar et al.}

Among the traffic movements 1 to 6 , movements 1 and 2 which are opposing through movements for road A are considered as Non-conflicting movements because they dont create conflict point. Movements 3 and 4 which are right turn movements from road A and road B respectively are considered as Conflicting movements and the movements 5 and 6 are free lefts which cause no traffic trouble.

\section{Objectives:}

The Objectives of this research are as follows:

- To develop critical gap and follow up-time for Indian road condition to take into consideration of vehicle composition.

- To analyze the effect of variation in parameters to the performance of unsignalised intersection calculated using the proposed procedure.

\section{Traffic Volume in PCU - From Balapur to TKR}

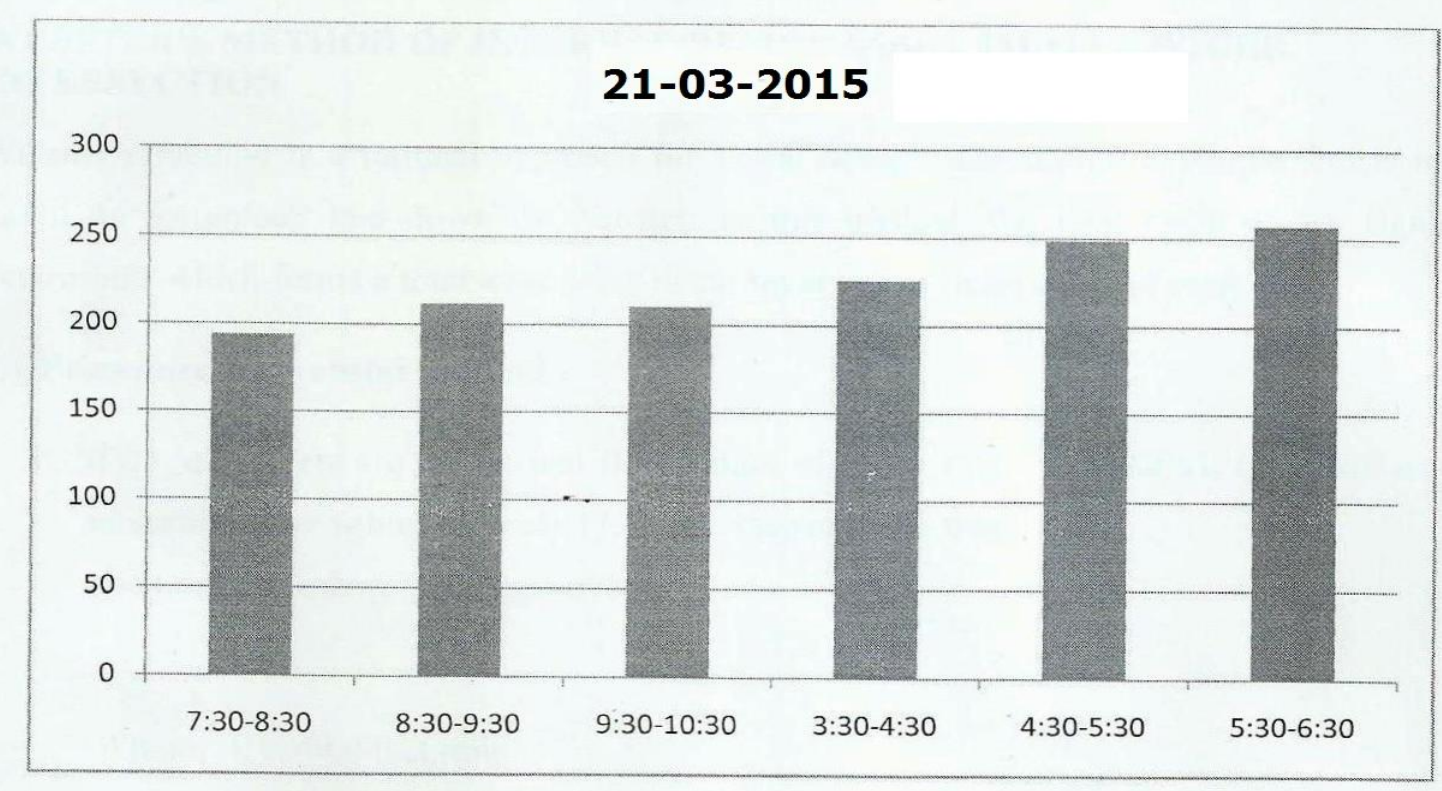

\begin{tabular}{|c|c|c|c|c|c|c|c|c|c|c|}
\hline Time & 2W & Cars & Buses & Mini Bus & Auto & LMV/Tractor & 2-Axle & 3-Axle & Total & PCU \\
\hline $07: 30-08: 30$ & 168 & 27 & 2 & 3 & 59 & 5 & 1 & 1 & 266 & 194 \\
\hline $08: 30-09: 30$ & 202 & 33 & 4 & 6 & 35 & 9 & 1 & 2 & 292 & 212.5 \\
\hline $09: 30-10: 30$ & 188 & 22 & 3 & 4 & 43 & 15 & 2 & 1 & 278 & 210.5 \\
\hline $03: 30-4: 30$ & 168 & 31 & 3 & 2 & 51 & 18 & 5 & 2 & 280 & 226 \\
\hline $04: 30-05: 30$ & 189 & 37 & 4 & 6 & 56 & 13 & 3 & 4 & 312 & 249 \\
\hline $05: 30-06: 30$ & 212 & 40 & 3 & 5 & 60 & 19 & 1 & 1 & 297 & 257 \\
\hline $\begin{array}{c}\text { Peak Hour } \\
\text { Morning } \\
(08: 30-09: 30)\end{array}$ & 202 & 33 & 4 & 6 & 35 & 9 & 1 & 2 & 292 & 212.5 \\
\hline $\begin{array}{c}\text { Peak Hour } \\
\text { Evening } \\
(05: 30-06: 30)\end{array}$ & 212 & 40 & 3 & 5 & 60 & 19 & 1 & 1 & 297 & 257 \\
\hline
\end{tabular}

\section{CONClusion}

- At TKR Kaman Junction there is a mixed flow of traffic. By analysis of the unsignalized intersection

- We found that there is a disturb in flow of traffic. Hence, at three-way intersection a signal should be designed. 
- Hence a signal timer as per the above mentioned windows and timings is suggested to be installed. And to further decrease disturbances caused by the pedestrians zebra crossings are to be installed at the junctions and the pedestrians are to be guided across on reds.

- And vehicular parking within the prescribed radius of the junctions is to be evoked and prohibited completely.

\section{REFERENCES}

[1] IRC-9-197 2 Traffic census of non-urban roads

[2] IRC-17-1977 Guidelines on re-population and control of mixed traffic in urban areas

[3] IRC-93-1985 Guidelines for design and installation of road traffic signals

[4] IRC-102-1 988 Traffic studies for planning by-pass around town

[5] IRC-106-1 990 Guidelines for capacity of urban roads in plain areas

[6] Currin, T. R. 2001. Turning Movement Counts. In Introduction to Traffic Engineering: A Manual 